\title{
PI3K mediates protection against TRAIL-induced apoptosis in primary human melanocytes
}

\author{
L Larribere ${ }^{1}$, M Khaled ${ }^{1}$, S Tartare-Deckert ${ }^{1}$, R Busca ${ }^{1}$, \\ F Luciano ${ }^{2}$, K Bille ${ }^{1}$, G Valony ${ }^{1}$, A Eychene ${ }^{3}$, P Auberger ${ }^{2}$, \\ JP Ortonne ${ }^{1}, \mathrm{R}$ Ballotti ${ }^{1}$ and C Bertolotto ${ }^{*, 1}$ \\ 1 INSERM U597, Biologie et pathologie des cellules mélanocytaires: de la \\ pigmentation cutanée aux mélanomes, Equipe labellisée par la Ligue \\ Nationale contre le Cancer, 28, avenue de Valombrose, 06107 Nice Cedex 2, \\ France \\ 2 INSERM U526, Physiopathologie de la mort et la survie cellulaires, Equipe \\ labellisée par la Ligue Nationale contre le Cancer, IFR 50, 28, avenue de \\ Valombrose, 06107 Nice Cedex 2, France \\ 3 Unité Mixte de Recherche-146 CNRS, Institut Curie, 91406 Orsay, France \\ * Corresponding author: C Bertolotto, INSERM U597, Biologie et pathologie des \\ cellules mélanocytaires: de la pigmentation cutanée aux mélanomes, Equipe \\ labellisée par la Ligue Nationale contre le Cancer, 28, avenue de Valombrose, \\ 06107 Nice Cedex 2, France. Tel: + 334933777 90; \\ Fax: + 334938114 04; E-mail: bertolot@unice.fr
}

Received 12.2.04; revised 13.4.04; accepted 27.4.04; published online 09.7.04 Edited by J Tschopp

\begin{abstract}
Melanocytes are cells of the epidermis that synthesize melanin, which is responsible for skin pigmentation. Transformation of melanocytes leads to melanoma, a highly aggressive neoplasm, which displays resistance to apoptosis. In this report, we demonstrate that TNF-related apoptosisinducing ligand (TRAIL), which was thought to kill only transformed cells, promotes very efficiently apoptosis of primary human melanocytes, leading to activation of caspases 8, 9 and 3, and the cleavage of vital proteins. Further, we show that stem cell factor (SCF), a physiologic melanocyte growth factor that activates both the phosphatidyl-inositol-3 kinase (PI3K) and the extracellular regulated kinase (ERK) pathways, strongly protects melanocytes from TRAIL and staurosporine killing. Interestingly, inhibition of PI3K or its downstream target AKT completely blocks the antiapoptotic effect of SCF, while inhibition of ERK has only a moderate effect. Our data indicate that protection evoked by SCF/PI3K/AKT cascade is not mediated by an increase in the intracellular level of FLIP. Further, only a sustained PI3K activity can protect melanocytes from apoptosis, thereby indicating that the PI3K/AKT pathway plays a pivotal role in melanocyte survival. The results gathered in this report bring new information on the molecular mechanisms involved in primary melanocyte apoptosis and survival that would help to better understand the process by which melanomas acquire their resistance to apoptosis.
\end{abstract}

Cell Death and Differentiation (2004) 11, 1084-1091.

doi:10.1038/sj.cdd. 4401475

Published online 9 July 2004

Keywords: apoptosis; ERK; melanocyte; PI3K; SCF; TRAIL

\begin{abstract}
Abbreviations: ERK, extracellular regulated kinase; HGF, hepatocyte growth factor; PARP, poly(ADP-ribose) polymerase; PI3K, phosphatidyl-inositol-3-kinase; SCF, stem cell factor; TRAIL, TNF-related apoptosis-inducing ligand
\end{abstract}

\section{Introduction}

Melanocytes are specialized cells of the epidermis that synthesize melanin. Melanin is responsible for skin pigmentation and plays a key photoprotective role against the harmful ultraviolet radiations of the solar light. The malignant transformation of melanocyte gives rise to melanoma, a highly aggressive, radiation- and chemotherapy-resistant neoplasm. Melanoma, whose incidence has strongly increased during the last few years and now concerns young and middle-aged people, has become a major medical problem. Melanoma, as many other neoplasms, gains specific traits that allow growth and metastasis development. Among these characteristics, it is well known that transformed cells and specially melanoma acquire a resistance to apoptosis mediated by anticancer drugs and death receptor ligands of the TNF family, which could explain a resistance to chemotherapy and the escape to the immune response.

Death receptors of the TNF family and their ligands are major actors of the apoptotic program. ${ }^{1,2}$ Hence, activation of fibroblast-associated (FAS) and TNF-related apoptosis-inducing ligand receptors (TRAIL-R1 and -2) by their respective ligands, Fas-L and TRAIL, promotes the activation of the initiator caspase 8. The onward cascade of apoptosis is the activation of the executive caspase 3 , which cleaves a number of vital proteins, including the DNA repair enzyme poly(ADPribose) polymerase (PARP), leading to DNA fragmentation and apoptotic cell death. ${ }^{3}$ In several cell types, apoptosis relies on the mitochondrial contribution to ultimately execute the apoptotic program. ${ }^{4}$ The mitochondrial network, which can also be initiated by stress signals such as anticancer drugs and irradiation, triggers the release of cytochrome $c$ from mitochondria. In the cytoplasm, cytochrome $c$, through binding to APAF-1, leads to activation of caspase 9, which in turn contributes to the stimulation of caspase $3{ }^{5,6}$ Several observations have pointed out to the involvement of the mitochondrial pathway in apoptosis of melanocytes and melanomas. ${ }^{7-9}$ Further, the resistance of melanoma to apoptosis has been ascribed to the alteration of the expression of proteins that control the mitochondria apoptosis pathway such as Bcl2, BcIXL and Apaf1. ${ }^{10}$

Very strikingly, the studies performed until now have shown that normal melanocytes were resistant to apoptosis evoked by death receptor commitment. ${ }^{11,12}$ These observations suggest the existence of strong survival signals in melanocyte cultures. Indeed, it is well known that melanocyte culture requires strong mitogenic and survival agents such as phorbol ester (PMA), which can be substituted by physiologic growth 
factors such as stem cell factor (SCF) and hepatocyte growth factor (HGF).

Interestingly, in vivo, SCF and HGF are produced by keratinocytes and fibroblasts and can act locally on melanocytes. The inhibition of SCF action in epidermis causes a dramatic reduction in melanocyte number and hair whitening. ${ }^{13,14}$ Further, transgenic mice expressing elevated levels of SCF develop melanocyte dysplasia. ${ }^{15}$ Interestingly, transgenic mice overexpressing HGF also develop melanocyte dysplasia and are prone to develop melanoma upon UV exposure. ${ }^{16} \mathrm{SCF}$ and HGF act through the activation of their cognate tyrosine kinase receptors, $\mathrm{c}$-Kit and c-Met respectively, and trigger the activation of the extracellular signalregulated kinase (ERK) and the phosphatidyl-inositol-3kinase (PI3K), two signalling pathways largely involved in proliferation and survival of several cell types. ${ }^{17-20}$

Thus, in this report, we have investigated the molecular mechanisms involved in death receptor-induced apoptosis of normal human melanocytes. We demonstrate for the first time that normal melanocytes are highly sensitive to apoptosis induced by TRAIL, which is generally not able to induce death in nontransformed cells. In agreement with a general resistance to apoptosis of tumor cells, we observe that melanoma cells are less sensitive to apoptotic stimuli than normal melanocytes. We also show that SCF protects melanocytes from TRAIL- and staurosporine-mediated apoptosis. Interestingly, we demonstrate that the PI3K/AKT pathway and the ERK pathway to a lesser extent play a key role in the antiapoptotic effect of SCF. However, sustained activation of the PI3K pathway, but not that of the ERK, is sufficient to prevent TRAIL-induced apoptosis of melanocytes.

As a whole, our results bring new information on the physiologic molecular mechanisms that govern human primary melanocyte apoptosis and survival. Further, taking into account that $\mathrm{PI} 3 \mathrm{~K}$ and ERK pathways are often activated in melanoma, our data will help us to better understand the respective role of $\mathrm{PI} 3 \mathrm{~K}$ and ERK pathways in the acquisition of the resistance to apoptosis during the etiopathogenesis of melanoma.

\section{Results}

\section{Human primary melanocytes and melanomas display different sensitivities to TRAIL-induced cell death}

First, we sought to determine the sensitivity of normal human melanocytes to several proapoptotic agents in the absence of growth factors in their culture medium. The effects of two death receptor ligands, $\mathrm{CH} 11$ (an antibody that mimics the effects of Fas-L) and TRAIL, and that of the protein kinase inhibitor staurosporine were assessed by the XTT dye reduction assay, an indicator of cell viability. As indicated by the percentage of viable cells in Figure 1a, TRAIL and staurosporine strongly decreased viability of primary human melanocytes by $90 \%$ (Figure 1a). Although to a less extent, TRAIL and staurosporine also reduced viability of the human WM9, Skmel3 and Skmel5 melanoma cell lines (Figure 1b). On the other hand, $\mathrm{CH} 11$ did not affect viability of normal melanocytes or that of melanomas. In conclusion, we show for
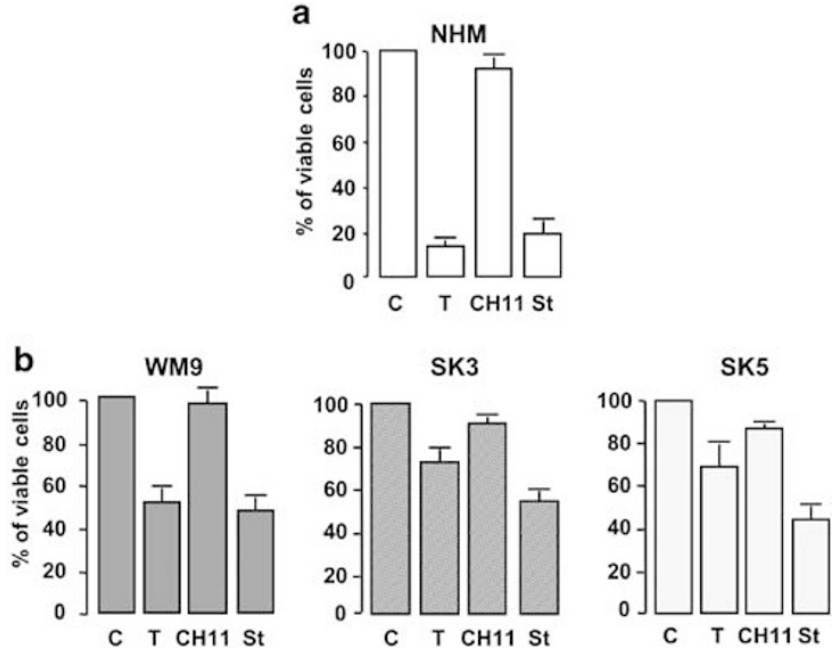

Figure 1 TRAIL decreases cell survival of human primary melanocytes and melanomas. (a) Primary human melanocytes $\left(2 \times 10^{3} /\right.$ well in triplicate) were incubated with TRAIL $25 \mathrm{ng} / \mathrm{ml}(\mathrm{T}), \mathrm{CH} 11100 \mathrm{ng} / \mathrm{ml}(\mathrm{CH} 11)$ or staurosporine $0.5 \mu \mathrm{M}$ (St) for $16 \mathrm{~h}$. (b) Human WM9, SKmel3 and SKmel5 melanoma cell lines were exposed to death inducers as in (a) except for TRAIL $100 \mathrm{ng} / \mathrm{ml}$. Cell survival was assessed by the XTT dye reduction assay, which measures mitochondrial respiratory function as described in Materials and methods. Cell viability is expressed as a percentage of that of control cells (c). Data are means \pm S.E.M. of three experiments performed in triplicate

the first time that TRAIL strongly decreased human primary melanocyte survival. Further, in agreement with a general resistance to death of tumor cells, our results indicate that TRAIL kills melanocytes more efficiently than melanomas.

\section{TRAIL mediates a rapid and massive apoptosis of human primary melanocytes but not of human primary keratinocytes or fibroblasts}

We next wished to investigate how TRAIL decreased melanocyte viability. Phase contrast microscopy showed that TRAIL changed primary melanocyte morphology causing neurite retraction and rounding shape, characteristic of cell death (Figure 2a). Interestingly, TRAIL effects on melanocyte viability and morphology were almost completely blocked in the presence of Ac-DEVD-fmk, an inhibitor of the caspase 3 family (Figure $2 a$ and $b$ ). All caspases are synthesized as inactive zymogens that need to be activated by proteolytic processing. Therefore, in Western blots, caspase activation can be followed by the disappearance of the zymogenic form that is detected by a specific antibody. In melanocytes, TRAIL promoted the processing of the procaspase 3 that was blocked upon Ac-DEVD-fmk treatment (Figure 2c).

We next looked for the effect of TRAIL in normal human keratinocytes and fibroblasts, two other skin cell types. As indicated by the percentage of viable cells and by detection of procaspase 3, TRAIL did not decrease viability of primary human keratinocytes and only induced a 15\% death of primary fibroblasts (Figure 2d and e). Staurosporine, used as a positive control, efficiently reduced viability of keratinocytes and fibroblasts by 50 and $70 \%$ respectively and promoted the processing of procaspase 3 . 

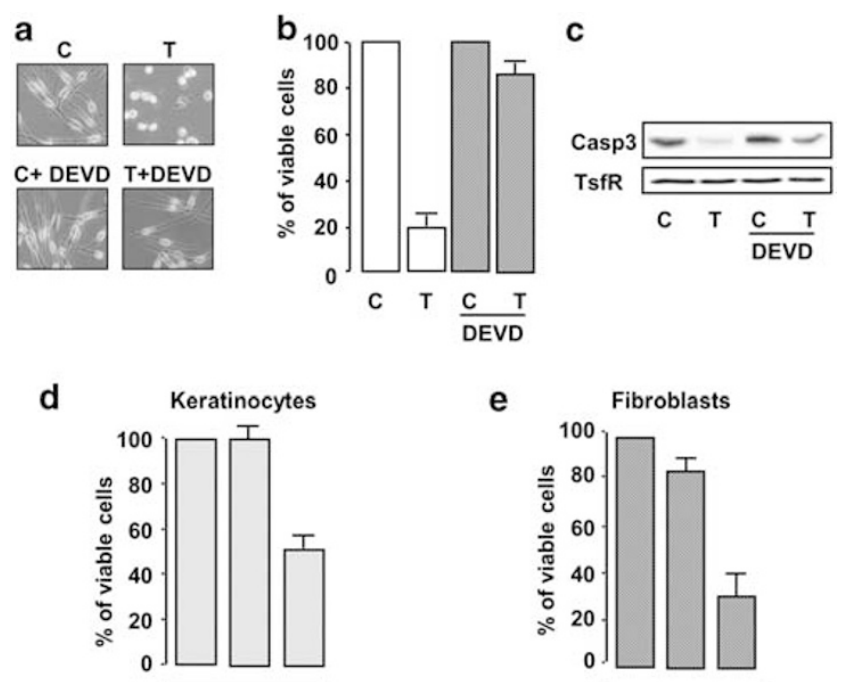

Casp3 $32-\frac{}{-}-\frac{-}{\text { C T St }}$

Casp3 $32-\frac{}{\text { C } \quad \text { T St }}$

Figure 2 TRAIL promotes apoptosis of human primary melanocytes. (a) Phase contrast microscopy images of human primary melanocytes in response to TRAIL $25 \mathrm{ng} / \mathrm{ml}(\mathrm{T})$ for $16 \mathrm{~h}$ in the presence or absence of $50 \mu \mathrm{M} \mathrm{Ac-DEVD-fmk.} \mathrm{(b)}$ Human primary melanocyte survival was assessed by the XTT dye reduction assay after treatment with TRAIL $25 \mathrm{ng} / \mathrm{ml}$ (T) for $16 \mathrm{~h}$ in the presence or absence of $50 \mu \mathrm{M} \mathrm{Ac-DEVD-fmk}$. Cell viability is expressed as a percentage of that of control cells (c). Data are means \pm S.E.M. of three experiments performed in triplicate. (c) Melanocyte lysates from (a) were analyzed by Western blot with procaspase 3-specific antibody or anti-transferrin receptor antibody. (d) Human primary keratinocytes or (e) human primary fibroblasts $\left(2 \times 10^{3} /\right.$ well in triplicate) were incubated with TRAlL $25 \mathrm{ng} / \mathrm{ml}$ or staurosporine $0.5 \mu \mathrm{M}$ for $16 \mathrm{~h}$. Cell viability is expressed as a percentage of that of control cells (c). Data are means \pm S.E.M. of three experiments performed in triplicate. Lysates of keratinocytes and fibroblasts were also analyzed for the expression of procaspase 3 (Casp3) by Western blot

Next, time course experiments clearly demonstrated that TRAIL induced a rapid procaspase 8 processing, which is visible after $30 \mathrm{~min}$ with TRAIL (Figure 3a). Processing of procaspase 9 and procaspase 3 followed after $60 \mathrm{~min}$. Further, we investigated the cleavage of PARP, the prototype of caspase 3 substrate, using an antibody that recognizes the $85 \mathrm{kDa}$ fragment, characteristic of apoptosis. The cleaved form of PARP was observed after $120 \mathrm{~min}$ with TRAIL (Figure $3 a$ ). Detection of the receptor for transferrin ensured that each lane was even-loaded. TRAIL-induced apoptosis was also dose dependent as shown by caspase 3 processing and cleavage of PARP in Western blotting (Figures 3b).

Together, these results clearly demonstrate that in normal melanocytes TRAIL first activates caspase 8, then caspase 9 and caspase 3 and leads to the cleavage of PARP, finally culminating in apoptosis.

Altogether, conversely to the primary idea indicating that TRAIL does not induce apoptosis in nontransformed cells, our observations show that normal human melanocytes display a strong sensitivity to the proapoptotic effect of TRAIL.

\section{SCF rescues melanocytes from TRAIL-induced apoptosis}

As SCF and HGF play a key role in melanocyte proliferation and survival, we aimed to evaluate their effect on TRAIL-

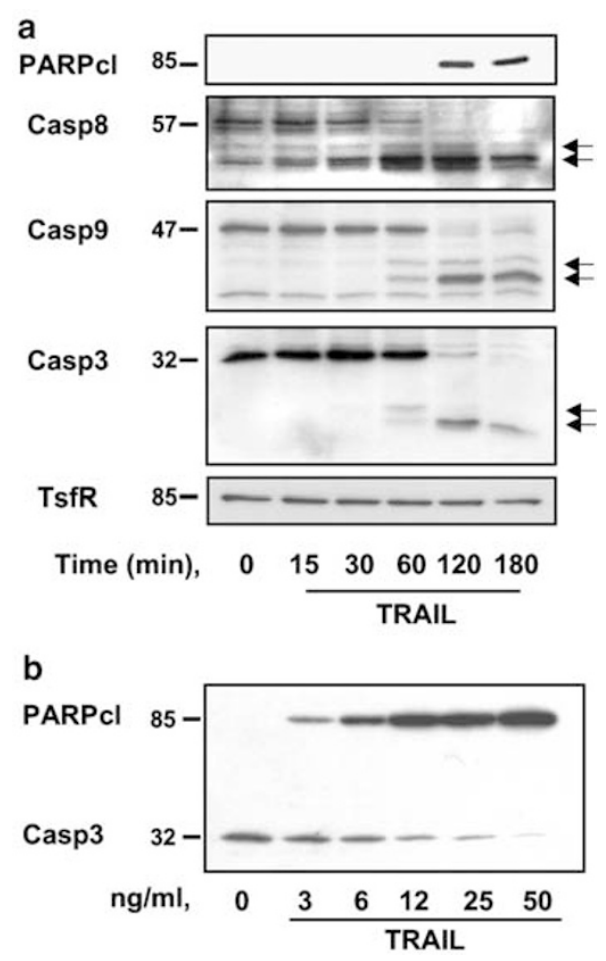

Figure 3 In human primary melanocytes, TRAIL activates the cascade of caspases and promotes the cleavage of PARP. (a) Human primary melanocytes were left untreated or were exposed to TRAIL $(25 \mathrm{ng} / \mathrm{ml})$ for the time indicated in the figure. Cell lysates were analyzed by Western blot with antibodies specific for procaspase 8 (Casp8), 9 (Casp9) or 3 (Casp3) and with an antibody that recognizes the cleaved form of PARP (PARPcl) at $85 \mathrm{kDa}$. Detection of transferrin receptor ensured even-loading of each lane. (b) Dose response of TRAIL ( $3 \mathrm{~h}$ ) in human primary melanocytes. Protein extracts were then submitted to immunoblotting using anti-procaspase 3 (Casp3) and cleaved PARP (PARPcl) antibodies

induced melanocyte death. We observed that SCF prevented TRAIL-mediated death of melanocytes, while HGF exerted a weak protective effect against TRAIL killing (Figure 4a, upper). TRAIL-induced caspase 3 processing was considerably reduced when melanocytes were treated with SCF compared to melanocytes exposed to TRAIL in the absence of SCF (lanes 2 and 4, Figure 4, lower panel). In agreement with the experiments of cell viability, HGF hardly inhibited the processing of caspase 3 caused by TRAIL. Therefore, our results demonstrate that SCF, but not HGF, strongly protects melanocytes from TRAIL-induced apoptosis.

In several cell types, HGF and SCF have been reported to signal through the activation of the PI3K and ERK pathways. Using phospho-specific antibodies against ERK and AKT, a downstream target of PI3K, we next evaluated the activation of the ERK and PI3K cascades in response to SCF and HGF.

We observed that SCF and HGF stimulated the ERK and PI3K/AKT pathways with different kinetics and intensity (Figure 4b). Quantitative analysis of the level of phosphospecific signal showed that SCF was a stronger activator of AKT than HGF. However, both growth factors activated AKT with a similar kinetic. HGF had a rapid, robust and sustained effect on ERK, while SCF also induced a rapid but transient activation of ERK. Detection of transferrin receptor ensured the even-loading of each lane. 


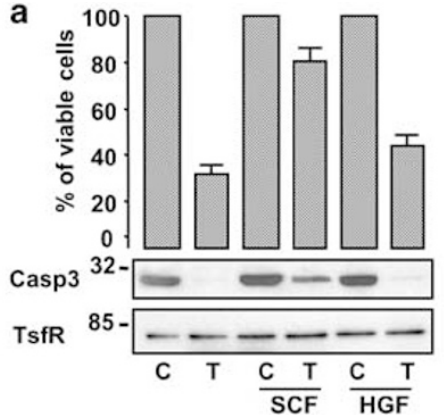

b TsfR $85-\square---\cdots$

pAKT

pERK1/2
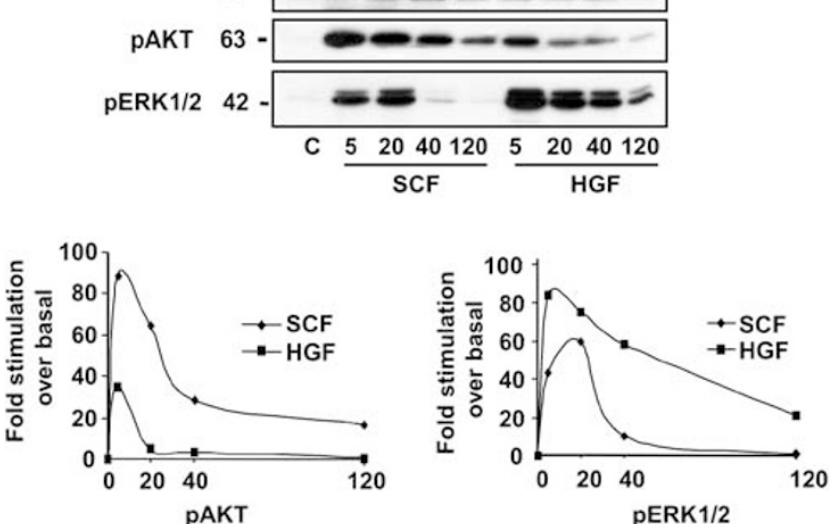

Figure 4 SCF protects normal melanocytes from TRAIL-induced apoptosis. (a) Viability of human primary melanocytes pretreated with SCF $(100 \mathrm{ng} / \mathrm{ml})$ or HGF $(100 \mathrm{ng} / \mathrm{ml})$ for $1 \mathrm{~h}$ and then incubated with TRAIL $(25 \mathrm{ng} / \mathrm{ml})$ or (b) staurosporine $(1 \mu \mathrm{M})$ for $3 \mathrm{~h}$ was measured by the XTT dye reduction assay. Cell viability is expressed as a percentage of that of control cells (c). Data are means + S.E.M of three experiments performed in triplicate. In parallel, protein extracts were subjected to Western blot with anti-procaspase 3 (Casp3) and transferrin receptor antibodies. (b) Time course experiments of primary melanocytes exposed to SCF $(100 \mathrm{ng} / \mathrm{ml})$ or HGF $(100 \mathrm{ng} / \mathrm{ml})$ for the time indicated in the figure. Western blot analysis of cell extracts with phospho-Ser473 AKT (pAKT) and phospho-Tyr204/Thr202 p42/44 ERK (pERK1/2). The resulting AKT and ERK phosphorylation levels were quantified using the $\mathrm{NIH}$ image software

Since SCF has a more pronounced protective effect than HGF effect, these results suggest that the PI3K route plays a key role in the antiapoptotic effect of SCF.

\section{SCF predominantly mediates its antiapoptotic effects through PI3K activation}

To investigate the role of the ERK and PI3K/AKT pathways in the prosurvival action of SCF, we used pharmacological inhibitors of ERK or PI3K and AKT. The protection evoked by SCF against TRAIL-induced apoptosis of melanocytes was reduced by about $30 \%$ in the presence of PD98059 and completely abrogated by LY294002 or AKT inhibitor (Figure 5a). Addition of PD98059 or LY294002 had no further effect. Western blot analysis showed that ERK and AKT activity was fully inhibited by PD98059 and LY294002, respectively, demonstrating the efficiency of the inhibitors on both signalling pathways (Figure $5 \mathrm{~b}$ ). Phosphorylation of GSK3 $\beta$ induced by SCF was prevented by AKT inhibitor, demonstrating its functionality (Figure $5 \mathrm{c}$ ).
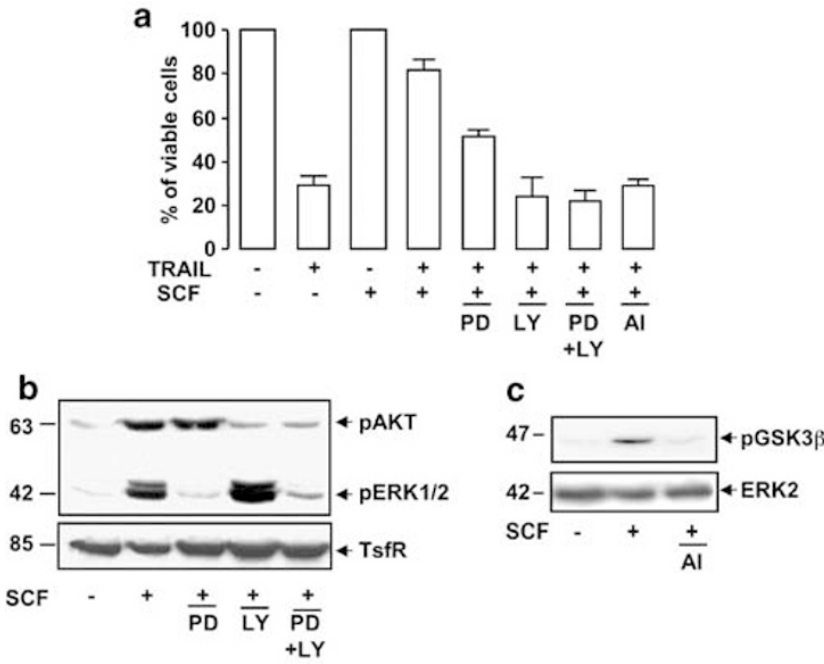

d
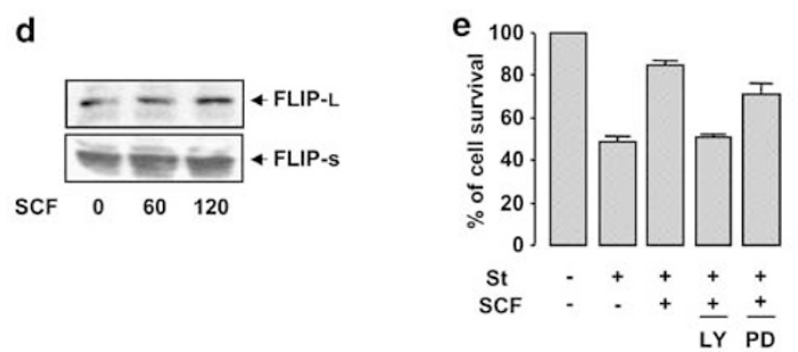

Figure 5 LY294002, AKT inhibitor and to a lesser extent PD98059 prevent the antiapoptotic effect of SCF. (a) Melanocytes were pretreated with SCF (100 ng/ $\mathrm{ml})$ for $1 \mathrm{~h}$ and then incubated for $3 \mathrm{~h}$ with TRAlL $(25 \mathrm{ng} / \mathrm{ml})$ in the presence or absence of LY294002 $(15 \mu \mathrm{M})$ or PD98059 $(20 \mu \mathrm{M})$ or AKT inhibitor $(20 \mu \mathrm{M})$. Cell viability is expressed as a percentage of that of control cells (c). Data are means \pm S.E.M. of three experiments performed in triplicate. (b) Lysates from melanocytes exposed to SCF in the presence or absence of LY294002 or PD98059 were submitted to immunoblotting with phospho-Ser473 AKT (pAKT) and phospho-Tyr204/Thr202 p42/44 ERK (pERK1/2). (c) Western blot of melanocyte lysates exposed to AKT inhibitor was revealed by a phospho-Ser9 GSK3 $\beta$ (pGSK3 $\beta$ ) antibody. (b, c) Detection of transferrin receptor ERK2 ensured that each lane was even-loaded. (d) Immunoblotting with antibodies against FLIP-L or FLIP-S of melanocyte extracts exposed to SCF $(100 \mathrm{ng} / \mathrm{ml})$ for 60 or $120 \mathrm{~min}$. (e) Melanocytes were pretreated with SCF $(100 \mathrm{ng} / \mathrm{ml})$ for $1 \mathrm{~h}$ and then incubated for $4 \mathrm{~h}$ with staurosporine $(\mathrm{St}, 1 \mu \mathrm{M})$ in the presence or absence of LY294002 $(15 \mu \mathrm{M})$ or PD98059 $(20 \mu \mathrm{M})$. Cell viability is expressed as a percentage of that of control cells (c). Data are means \pm S.E.M. of three experiments performed in triplicate

The PI3K/AKT has been shown to exert its antiapoptotic activity by increasing the intracellular level of FLIP. However, short-term treatment of normal melanocytes with SCF did not affect FLIP-L or FLIP-s expression (Figure $5 \mathrm{~d}$ ).

Cell viability assay demonstrated that SCF also inhibited chemical-induced apoptosis elicited by staurosporine (Figure 5e). Further, inhibition of the PI3K/AKT pathway by LY294002 abrogated the antiapoptotic activity of SCF, while in the same condition PD98059 had a less significant effect.

The results show that SCF prevents both death and nondeath receptor-induced apoptosis, predominantly through the activation of the PI3K/AKT pathway.

To confirm this hypothesis, normal melanocytes were infected with an adenovirus encoding a constitutively active form of the catalytic subunit of the PI3K (p110) or a constitutively active BRAF and then were exposed to TRAIL. 
It is noteworthy that the adenovirus vector infected more than $90 \%$ of primary melanocytes. Phase contrast microscopy showed that infection of the human melanocytes with the adenovirus p110 almost completely blocked the morphologic cell change and the induction of melanocyte death caused by TRAIL as compared to melanocytes infected with an empty adenovirus or the BRAF adenovirus (Figure $6 a$ and b). Further, when normal melanocytes were infected with $\mathrm{p} 110$, TRAIL-mediated procaspase 3 processing was strongly inhibited conversely to control condition or in the presence of active BRAF (Figure 6c). The efficiency of the constitutively active PI3K or BRAF was confirmed by their ability to induce a robust AKT and ERK activity. In conclusion, our data clearly demonstrate that the activation of the PI3K pathway, but not that of the ERK pathway, is sufficient to induce melanocyte survival.

a

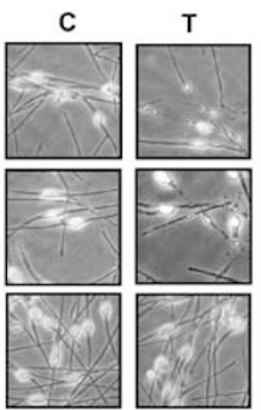

b

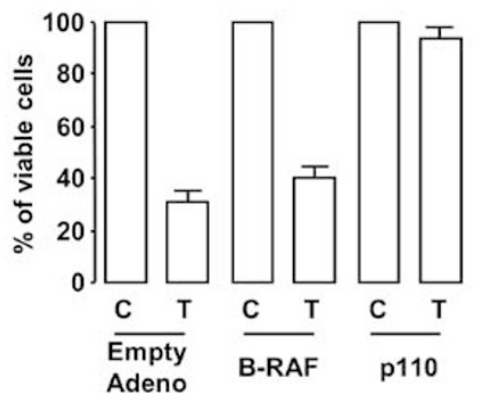

C

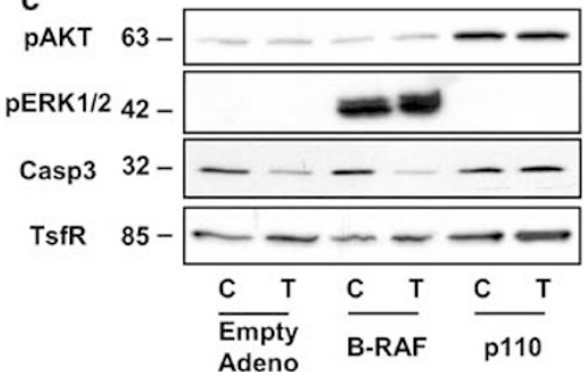

Figure 6 PI3K blocks TRAIL-induced apoptosis of melanocytes. (a) Phase contrast microscopy of human primary melanocytes exposed for $3 \mathrm{~h}$ to TRAIL $(25 \mathrm{ng} / \mathrm{ml})$ after infection with an empty adenovirus or adenoviruses encoding either an active form of the catalytic subunit of PI3K (p110) or an active form of BRAF (BRAF). (b) Viability of melanocytes treated as in (a) was evaluated and expressed as a percentage of that of control cells (c). Data are means \pm S.E.M. of three experiments performed in triplicate. (c) Western blot analysis of melanocytes shown in (a) with antibodies against phospho-Ser473 AKT (pAKT), phospho-Thr202/Tyr204 ERK1/2 (pERK1/2), procaspase 3 and transferrin receptor

\section{Discussion}

In the present report, we have undertaken a study of the mechanisms involved in normal human melanocytes apoptosis and survival. We demonstrated for the first time that TRAIL promoted very efficiently apoptosis of primary human melanocytes. TRAIL has been initially described to specifically induce apoptosis in a wide range of transformed and cancer cells, including melanomas, without affecting normal cells. ${ }^{21}$ Consistently, we observed that human primary keratinocytes or normal human skin fibroblasts were resistant to TRAILmediated apoptosis. In both cells types, the intrinsic death machinery was functional, since keratinocytes and fibroblasts were efficiently killed by staurosporine, a general inhibitor of protein kinases, often used for its ability to drive rapidly the majority of mammalian cells into apoptosis. ${ }^{22,23}$ However, a recent report indicates that human primary hepatocytes, upon growth factor withdrawal, can be efficiently killed by TRAIL, thereby indicating that TRAIL could promote apoptosis of normal cells. ${ }^{24}$ Interestingly, we observed that normal melanocytes were much sensitive to TRAIL-induced apoptosis than hepatocytes. Normal melanocytes have been shown to be resistant to TRAIL-induced apoptosis but, in these previous studies, melanocytes were grown in a defined medium containing several mitogens, including PMA that could block TRAIL-induced apoptosis. ${ }^{11,25}$ Here, we demonstrate that in the absence of such mitogens, TRAIL caused very efficiently apoptosis in primary human melanocytes.

Analysis of TRAIL receptor expression (DR1, DR2, DR4, DR5) indicated that the responsiveness to TRAIL of the different cell types used in this study did not directly rely on receptor expression (data not shown), and this is noteworthy.

In normal melanocytes, TRAIL promoted the activation of the initiator caspase 8 and then that of caspase 9 and caspase 3 , indicating that TRAIL effect involved the mitochondrial network. These results agree with the observations made in melanomas, which demonstrate the key contribution of mitochondria in TRAIL-mediated apoptosis. ${ }^{26-28}$ In the same conditions, $\mathrm{CH} 11$, an IgM that mimics the effect of FAS-L, did not significantly affect the viability of both normal melanocytes and melanomas. The susceptibility to TRAIL ligand but not to FAS-L has already been demonstrated in a variant of Jurkat Tcell line. In this case, it has been suggested that a factor, present in the cytosol, impeded the function of the truncated $\mathrm{Bid}$, which controls the release of cytochrome $c$, suggesting that the function of Bid is crucial for FAS signalling but can be overcome by TRAIL. ${ }^{29}$ Additional studies in melanocytes and melanomas are required to better understand their resistance to FAS-L-mediated killing.

Further, our results show that normal melanocytes are more sensitive to different apoptotic stimuli than melanomas, in agreement with the notion that resistance to apoptosis is a common characteristic of tumor cells. ${ }^{10,30}$

Consistent with an antiapoptotic action of some mitogens in the culture medium of melanocytes, we demonstrated that SCF, a physiologic melanocyte survival factor, protected melanocytes from TRAIL-induced apoptosis. Indeed, SCF potently reduced TRAIL-mediated caspase activation and melanocyte death. SCF also decreased killing of melanocytes by staurosporine. HGF, another melanocyte growth factor, 
exerted only very weak protective effect against apoptosis elicited by TRAIL. These results are in agreement with previous experiments, which showed that blocking SCF function caused murine melanocyte precursors apoptosis. ${ }^{14}$ On the other hand, deficiency in HGF or its receptor Met does not cause melanocyte loss, indicating that HGF is not absolutely required for melanocyte survival ${ }^{31}$ and $\mathrm{HGF}$ alone is not sufficient for the malignant transformation of melanocytes. $^{32-34}$ Taken together, our data emphasize the key role of SCF in melanocyte survival.

Interestingly, we showed that both SCF and HGF stimulated the ERK and PI3K/AKT signalling pathways. However, in primary melanocytes, SCF was a more potent activator of AKT than HGF, while the latter caused a stronger and sustained stimulation of ERK activity. Since SCF almost completely abolished TRAIL-mediated cell death, while HGF was poorly antiapoptotic, these observations suggest that the PI3K/AKT pathway is essential for the survival effect of SCF. Using pharmacological inhibitors of ERK (PD98059) and PI3K/AKT (LY294002 or AKT inhibitor) pathways, we confirmed this hypothesis by demonstrating that LY294002 or AKT inhibitor prevented the antiapoptotic effect of SCF, while PD98059 effect was partial. Additionally, we also showed that forced expression of an activated PI3K catalytic subunit blocked TRAIL-induced apoptosis in normal melanocytes. On the other hand, sustained activation of ERK, by expression of an active BRAF construct, did not affect TRAIL-induced melanocyte death.

Together, these results show that the PI3K route, and ERK pathway to a much lesser extent, plays a role in the antiapoptotic effect of SCF. However, the activation of ERK pathway alone is not sufficient to protect melanocytes from apoptosis.

Recent investigations have demonstrated that $66 \%$ of melanomas contain an activating mutation of BRAF leading to a strong and sustained ERK activity. ${ }^{35,36}$ Knockdown of BRAF expression induced apoptosis in melanoma bearing BRAF-activating mutation ${ }^{37,38}$ and inhibition of ERK $1 / 2$ by pharmacological inhibitors increased melanoma sensitivity to TRAIL. ${ }^{27}$ However, results from the literature showing that BRAF-activating mutations were also detected in benign nevi support the notion that the BRAF/MEK/ERK cascade is not sufficient by itself to promote melanocyte transformation and the characteristic resistance to apoptosis of the transformed cells. ${ }^{39,40}$ These observations are in agreement with our results demonstrating that the only activation of ERK is not sufficient to promote a resistance to apoptosis of melanocytes.

Thus, the passage from the benign melanocyte hyperplasia (nevus) to the malignant melanoma requires, in addition to ERK pathway activation, the deregulation of other antiapoptotic pathways.

Interestingly, the activation of PI3K is a very potent antiapoptotic signal and several reports have evoked the role of the PI3K pathway in melanoma tumorigenicity and resistance to apoptosis. ${ }^{41-43}$ Further, PTEN, a phospholipid phosphatase that downregulates the PI3K pathway, is often inactivated in melanoma. ${ }^{44}$ These observations and our results point out to the key role of the PI3K pathway in survival of melanocytes and development of melanoma. The
PI3K/AKT pathway has been shown to exert its antiapoptotic effect through regulation of FLIP ${ }^{45,46}$ However, in normal melanocytes, SCF did not change the intracellular level of FLIP-L or FLIP-S, indicating that FLIP does not mediate the antiapoptotic effect of SCF. The fact that SCF also protected melanocytes from staurosporine-induced apoptosis led us to envision that the SCF/PI3K/AKT cascade acts at the mitochondrial level to prevent melanocyte apoptosis.

As mentioned above, SCF is a survival factor for melanocytes and is required for proper development of the melanocytes. Interestingly, in vitiligo, a decreased level of SCF has been found in the depigmented zone, in which melanocytes were thought to die by apoptosis. ${ }^{47,48}$ Further, SCF production by keratinocytes is increased by ultraviolet $B$ (UVB) radiation, which is known to increase nevi size and number. ${ }^{49,50}$ In the same line, transgenic mice expressing elevated levels of SCF develop melanocyte dysplasia. ${ }^{51}$ Thus, SCF by preventing apoptosis in melanocytes could favor melanocyte growth and transformation.

Altogether, the results gathered in this study bring new information on the molecular mechanisms involved in primary melanocyte survival and apoptosis that could help in understanding the etiopathogenesis of melanomas or that of some pigmentary defects that affect melanocyte homeostasis.

\section{Materials and Methods}

\section{Materials}

Staurosporine, hydrocortisone, insulin, phorbol-12 myristate 13-acetate, MCDB 153 medium, sodium fluoride, sodium orthovanadate, 4-(2aminoethyl)-benzene-sulfonyl fluoride (AEBSF), aprotinin and leupeptin were purchased from Sigma Chem. Co (St. Louis, MO, USA). The MEK inhibitor PD98059, the PI3K inhibitor LY294002, the AKT inhibitor and the protease inhibitor acetyl-DEVD-fmk were from MERCK Eurolab. Dulbecco's modified Eagle's medium (DMEM) and trypsin were from Invitrogen (San Diego, CA, USA), fetal calf serum (FCS) was from Hyclone and KSFM was from Promocell (Heidelberg, Germany). Recombinant TRAIL, HGF and SCF (Val114-GlyGly281, described by Ashkenazi et al. ${ }^{52}$ were obtained from R\&D. Recombinant basic fibroblast growth factor was from Promega Co (Madison, WI, USA). Adenovirus encoding p110-CAAX was kindly provided by L Pirola (INSERM U145, France).

\section{Antibodies}

$\mathrm{CH} 11$, an IgM that mimics the effect of Fas-L, and monoclonal procaspase 3 (Casp3) antibodies were from Euromedex. The polyclonal procaspase 8 (Casp8), procaspase 9 (Casp9), cleaved PARP (PARPcl), phosphospecific Ser473 AKT (pAKT), total AKT, phospho-specific Ser9 GSK3 $\beta$ (pGSK3 $\beta$ ) and Thr202/Tyr204 ERK1/2 (pERK1/2) antibodies were from Cell Signaling Technology Inc. (Beverly). The monoclonal anti-transferrin receptor antibody was from Zymed Laboratories Inc. (CA, USA) and the monoclonal anti-ERK2 (D-2) antibody was from Santa Cruz Biotechnology. Horseradish peroxidase-conjugated anti-rabbit or anti-mouse antibodies were from Dakopatts (Glostrup, Denmark).

\section{Cell cultures}

Epidermal cell suspensions were obtained from foreskins of Caucasian children by overnight digestion in phosphate-buffered saline containing 
$0.5 \%$ dispase grade II at $4{ }^{\circ} \mathrm{C}$, followed by a 20 min digestion with $0.05 \%$ trypsin- $0.02 \%$ EDTA in phosphate-buffered saline (V/V) at $37^{\circ} \mathrm{C}$. Human primary melanocytes were grown in MCDB153 medium supplemented with $2 \%$ FCS, $0.4 \mu \mathrm{g} / \mathrm{ml}$ hydrocortisone, $5 \mu \mathrm{g} / \mathrm{ml}$ insulin, $16 \mathrm{nM}$ phorbol- 12 myristate 13-acetate, $1 \mathrm{ng} / \mathrm{ml}$ basic fibroblast growth factor, $10 \mu \mathrm{g} / \mathrm{ml}$ bovine pituitary extract and penicillin/streptomycin $(100 \mathrm{U} / \mathrm{ml} / 50 \mu \mathrm{g} / \mathrm{ml})$. Human primary keratinocytes were cultured in KSFM medium in which $0.1 \mathrm{ng} / \mathrm{ml}$ epidermal growth factor, $15 \mu \mathrm{g} / \mathrm{ml}$ bovine pituitary extract and penicillin/streptomycin $(100 \mathrm{U} / \mathrm{ml} / 50 \mu \mathrm{g} / \mathrm{ml})$ were added. Human primary fibroblasts, derived from the corresponding dermis, were grown in DMEM $7 \%$ FCS and penicillin/streptomycin $(100 \mathrm{U} / \mathrm{ml} / 50 \mu \mathrm{g} / \mathrm{ml})$. Human WM9, SKmel3 and SKmel5 melanoma cells were grown in DMEM supplemented with $7 \% \mathrm{FCS}$ and penicillin/streptomycin $(100 \mathrm{U} / \mathrm{ml} / 50 \mu \mathrm{g} / \mathrm{ml})$. All cell types were maintained in a humidified atmosphere containing $5 \% \mathrm{CO}_{2}$ at $37^{\circ} \mathrm{C}$. For all experiments, before being exposed to the different effectors, primary melanocytes were cultured for $16 \mathrm{~h}$ in MCDB153, $2 \% \mathrm{FCS}, 0.4 \mu \mathrm{g} /$ $\mathrm{ml}$ hydrocortisone, $5 \mu \mathrm{g} / \mathrm{ml}$ insulin; keratinocytes were depleted in KSFM serum free medium and melanomas and fibroblasts in DMEM serum free medium.

\section{Cell viability test}

Cell viability was assessed using the cell proliferation kit II (XTT; Roche Molecular Biochemicals, Indianapolis, IN, USA) according to the manufacturer's protocol. Briefly, cells $\left(2 \times 10^{4}\right.$ cells per point) were grown in triplicate in $100 \mu$ l of the corresponding medium before being starved of mitogens and growth factor for overnight. Cells were next treated with TRAIL, CH11 or staurosporine for the time indicated in the legend and then were incubated with the dye. Cell viability, measured at $490 \mathrm{~nm}$, is expressed as a percentage of that of control cells.

\section{Western blot assays}

Cells were grown in six-well dishes with or without different effectors for the time indicated in the figure. Then, cells were lysed in buffer A containing $50 \mathrm{mM}$ Tris $\mathrm{pH} 7.4,150 \mathrm{mM} \mathrm{NaCl}, 1 \%$ Triton X-100, $10 \mu \mathrm{M}$ leupeptin, $1 \mathrm{mM}$ AEBSF, $100 \mathrm{U} / \mathrm{ml}$ aprotinin, $10 \mathrm{mM} \mathrm{NaF}$ and $1 \mathrm{mM} \mathrm{Na} \mathrm{VO}_{4}$. Samples $(30 \mu \mathrm{g})$ were separated by $10 \%$ SDS-PAGE, transferred onto a PVDF membrane (Immobilon, Millipore, France) and then exposed to the appropriate antibodies. Proteins were visualized with the ECL system from Amersham using horseradish peroxidase-conjugated anti-rabbit or antimouse secondary antibody.

\section{Adenovirus construction and infection of primary melanocytes}

Generation of recombinant adenoviruses using the VmAdcDNA3 system has been previously described. ${ }^{53}$ Briefly, pCDNA3 encoding BRAFCAAX was recombined with VmAdcDNA3 into competent Escherichia coli BJ5183 (Stratagene, La Jolla, CA, USA). Recombinants were screened by PCR and amplified in JM109 cells. The recombinant adenoviral vector encoding BRAFCAAX was digested by Pacl before being transfected into human embryonic kidney 293 cells with Lipofectamine (Invitrogen) and the resulting viruses were serially amplified in 293 cells. Briefly, adenoviruses were harvested $36-40 \mathrm{~h}$ after infection, pelleted, lysed by three freezethaw cycles and stored in PBS. Viral titer of stocks was $\geqslant 10^{8} \mathrm{PFU} / \mathrm{ml}$. Transduction efficiency of melanocytes was determined using an adenoviral vector carrying the green fluorescent protein. ${ }^{54}$ An adenovirus consisting of the identical adenovirus backbone without cDNA insert (empty Adeno) was used as control. Primary melanocytes were infected with empty, p110CAAX or BRAFCAAX adenovirus at a multiplicity of infection (MOI) of 3 for $48 \mathrm{~h}$ before being exposed to TRAIL $(25 \mathrm{ng} / \mathrm{ml}$ ) for $3 \mathrm{~h}$. Cells were then lysed and the resulting protein extracts were analyzed by Western blotting.

\section{Acknowledgements}

The WM9 human melanoma cell line was kindly provided by M Herlyn (Philadelphia, USA). The VmAdcDNA3 plasmid was a kind gift of $S$ Rusconi (Fribourg, Switzerland). This work was supported by INSERM, The Ligue Nationale contre le Cancer, the Association pour la Recherche sur le Cancer grant 5808 and Leo Pharma group.

\section{References}

1. Ashkenazi A and Dixit VM (1998) Death receptors: signaling, modulation. Science 281: 1305-1308

2. LeBlanc HN and Ashkenazi A (2003) Apo2L/TRAIL and its death and decoy receptors. Cell Death Differ. 10: 66-75

3. Hasegawa J, Kamada S, Kamiike W, Shimizu S, Imazu T, Matsuda H and Tsujimoto Y (1996) Involvement of CPP32/Yama(-like) proteases in Fasmediated apoptosis. Cancer Res. 56: 1713-1718

4. Peter ME and Krammer PH (1998) Mechanisms of CD95 (APO-1/Fas)mediated apoptosis. Curr. Opin. Immunol. 10: 545-551

5. Kroemer G (1997) The proto-oncogene Bcl-2 and its role in regulating apoptosis. Nat. Med. 3: 614-620

6. Kroemer G, Zamzami N and Susin SA (1997) Mitochondrial control of apoptosis. Immunol. Today 18: 44-51

7. Veis DJ, Sorenson CM, Shutter JR and Korsmeyer SJ (1993) Bcl-2-deficient mice demonstrate fulminant lymphoid apoptosis, polycystic kidneys, and hypopigmented hair. Cell 75: 229-240

8. Zhai S, Yaar M, Doyle SM and Gilchrest BA (1996) Nerve growth factor rescues pigment cells from ultraviolet-induced apoptosis by upregulating BCL-2 levels. Exp. Cell Res. 224: 335-343

9. McGill GG, Horstmann M, Widlund HR, Du J, Motyckova G, Nishimura EK, Lin YL, Ramaswamy S, Avery W, Ding HF, Jordan SA, Jackson IJ, Korsmeyer SJ, Golub TR and Fisher DE (2002) Bcl2 regulation by the melanocyte master regulator mitf modulates lineage survival and melanoma cell viability. Cell 109: 707-718

10. Hussein MR, Haemel AK and Wood GS (2003) Apoptosis and melanoma: molecular mechanisms. J. Pathol. 199: 275-288

11. Griffith TS, Chin WA, Jackson GC, Lynch DH and Kubin MZ (1998) Intracellular regulation of TRAIL-induced apoptosis in human melanoma cells. J. Immunol. 161: 2833-2840

12. Zhang XD, Nguyen T, Thomas WD, Sanders JE and Hersey $P(2000)$ Mechanisms of resistance of normal cells to TRAIL induced apoptosis vary between different cell types. FEBS Lett. 482: 193-199

13. Spritz RA (1994) Molecular basis of human piebaldism. J. Invest. Dermatol. 103: $137 \mathrm{~S}-140 \mathrm{~S}$

14. Ito $\mathrm{M}$, Kawa $\mathrm{Y}$, Ono $\mathrm{H}$, Okura $\mathrm{M}$, Baba $\mathrm{T}$, Kubota $\mathrm{Y}$, Nishikawa $\mathrm{SI}$ and Mizoguchi M (1999) Removal of stem cell factor or addition of monoclonal antic-KIT antibody induces apoptosis in murine melanocyte precursors. J. Invest. Dermatol. 112: 796-801

15. Kunisada T, Lu SZ, Yoshida H, Nishikawa S, Mizoguchi M, Hayashi S, Tyrrell L, Williams DA, Wang $X$ and Longley BJ (1998a) Murine cutaneous mastocytosis and epidermal melanocytosis induced by keratinocyte expression of transgenic stem cell factor. J. Exp. Med. 187: 1565-1573

16. Noonan FP, Recio JA, Takayama H, Duray P, Anver MR, Rush WL, De Fabo $E C$ and Merlino $G$ (2001) Neonatal sunburn and melanoma in mice. Nature 413: 271-272

17. Neri LM, Borgatti P, Capitani S and Martelli AM (2002) The nuclear phosphoinositide 3-kinase/AKT pathway: a new second messenger system. Biochim. Biophys. Acta 1584: 73-80 
18. Chang F, Lee JT, Navolanic PM, Steelman LS, Shelton JG, Blalock WL Franklin RA and McCubrey JA (2003a) Involvement of PI3K/Akt pathway in cell cycle progression, apoptosis, and neoplastic transformation: a target for cancer chemotherapy. Leukemia 17: 590-603

19. Chang F, Steelman LS, Lee JT, Shelton JG, Navolanic PM, Blalock WL, Franklin RA and McCubrey JA (2003b) Signal transduction mediated by the Ras/Raf/MEK/ERK pathway from cytokine receptors to transcription factors: potential targeting for therapeutic intervention. Leukemia 17: 1263-1293

20. Reddy KB, Nabha SM and Atanaskova N (2003) Role of MAP kinase in tumor progression and invasion. Cancer Metastasis Rev. 22: 395-403

21. Srivastava RK (2001) TRAIL/Apo-2L: mechanisms and clinical applications in cancer. Neoplasia 3: 535-546

22. Gescher A (1998) Analogs of staurosporine: potential anticancer drugs? Gen Pharmacol. 31: 721-728

23. Stepczynska A, Lauber K, Engels IH, Janssen O, Kabelitz D, Wesselborg S and Schulze-Osthoff K (2001) Staurosporine and conventional anticancer drugs induce overlapping, yet distinct pathways of apoptosis and caspase activation. Oncogene 20: 1193-1202

24. Jo M, Kim TH, Seol DW, Esplen JE, Dorko K, Billiar TR and Strom SC (2000) Apoptosis induced in normal human hepatocytes by tumor necrosis factorrelated apoptosis-inducing ligand. Nat. Med. 6: 564-567

25. Thomas WD and Hersey P (1998) TNF-related apoptosis-inducing ligand (TRAIL) induces apoptosis in Fas ligand-resistant melanoma cells and mediates CD4T cell killing of target cells. J. Immunol. 161: 2195-2200

26. Thomas WD, Zhang XD, Franco AV, Nguyen T and Hersey P (2000) TNFrelated apoptosis-inducing ligand-induced apoptosis of melanoma is associated with changes in mitochondrial membrane potential and perinuclear clustering of mitochondria. J. Immunol. 165: 5612-5620

27. Zhang XD, Borrow JM, Zhang XY, Nguyen T and Hersey $P$ (2003) Activation of ERK $1 / 2$ protects melanoma cells from TRAIL-induced apoptosis by inhibiting Smac/DIABLO release from mitochondria. Oncogene 22: 2869-2881

28. Zhang XD, Zhang XY, Gray CP, Nguyen T and Hersey P (2001) Tumor necrosis factor-related apoptosis-inducing ligand-induced apoptosis of human melanoma is regulated by smac/DIABLO release from mitochondria. Cancer Res. 61: 7339-7348

29. Werner AB, de Vries E, Tait SW, Bontjer I and Borst J (2002) TRAIL receptor and CD95 signal to mitochondria via FADD, caspase-8/10, Bid, and Bax but differentially regulate events downstream from truncated Bid. J. Biol. Chem. 277: 40760-40767

30. Helmbach H, Rossmann E, Kern MA and Schadendorf D (2001) Drugresistance in human melanoma. Int. J. Cancer 93: 617-622

31. Kos L, Aronzon A, Takayama H, Maina F, Ponzetto C, Merlino G and Pavan W (1999) Hepatocyte growth factor/scatter factor-MET signaling in neural crestderived melanocyte development. Pigment Cell Res. 12: 13-21

32. Otsuka T, Takayama H, Sharp R, Celli G, LaRochelle WJ, Bottaro DP, Ellmore N, Vieira W, Owens JW, Anver M and Merlino G (1998) c-Met autocrine activation induces development of malignant melanoma and acquisition of the metastatic phenotype. Cancer Res. 58: 5157-5167

33. Hamoen KE, Borel Rinkes IH and Morgan JR (2001) Hepatocyte growth factor and melanoma: gene transfer studies in human melanocytes. Melanoma Res. 11: $89-97$

34. Li G, Schaider H, Satyamoorthy K, Hanakawa Y, Hashimoto K and Herlyn M (2001) Downregulation of E-cadherin and Desmoglein 1 by autocrine hepatocyte growth factor during melanoma development. Oncogene 20: 8125-8135

35. Brose MS, Volpe P, Feldman M, Kumar M, Rishi I, Gerrero R, Einhorn E, Herlyn M, Minna J, Nicholson A, Roth JA, Albelda SM, Davies H, Cox C, Brignell G, Stephens P, Futreal PA, Wooster R, Stratton MR and Weber BL (2002) BRAF and RAS mutations in human lung cancer and melanoma. Cancer Res. 62: 6997-7000

36. Davies H, Bignell GR, Cox C, Stephens P, Edkins S, Clegg S, Teague J, Woffendin H, Garnett MJ, Bottomley W, Davis N, Dicks E, Ewing R, Floyd Y, Gray K, Hall S, Hawes R, Hughes J, Kosmidou V, Menzies A, Mould C, Parker A, Stevens C, Watt S, Hooper S, Wilson R, Jayatilake H, Gusterson BA, Cooper C, Shipley J, Hargrave D, Pritchard-Jones K, Maitland N, Chenevix-Trench G Riggins GJ, Bigner DD, Palmieri G, Cossu A, Flanagan A, Nicholson A, Ho JW, Leung SY, Yuen ST, Weber BL, Seigler HF, Darrow TL, Paterson H, Marais R, Marshall CJ, Wooster R, Stratton MR and Futreal PA (2002) Mutations of the BRAF gene in human cancer. Nature 417: 949-954
37. Calipel A, Lefevre G, Pouponnot C, Mouriaux F, Eychene A and Mascarelli F (2003) Mutation of B-Raf in human choroidal melanoma cells mediates cell proliferation and transformation through the MEK/ERK pathway. J. Biol. Chem. 278: 42409-42418

38. Hingorani SR, Jacobetz MA, Robertson GP, Herlyn M and Tuveson DA (2003) Suppression of BRAF(V599E) in human melanoma abrogates transformation. Cancer Res. 63: 5198-5202

39. Pollock PM, Harper UL, Hansen KS, Yudt LM, Stark M, Robbins CM, Moses TY, Hostetter G, Wagner U, Kakareka J, Salem G, Pohida T, Heenan P, Duray P, Kallioniemi O, Hayward NK, Trent JM and Meltzer PS (2003) High frequency of BRAF mutations in nevi. Nat. Genet. 33: 19-20

40. Uribe P, Wistuba II and Gonzalez S (2003) BRAF mutation: a frequent event in benign, atypical, and malignant melanocytic lesions of the skin. Am. J. Dermatopathol. 25: 365-370

41. Krasilnikov M, Ivanov VN, Dong J and Ronai Z (2003) ERK and PI3K negatively regulate STAT-transcriptional activities in human melanoma cells: implications towards sensitization to apoptosis. Oncogene 22: 4092-4101

42. Murakami T, Cardones AR, Finkelstein SE, Restifo NP, Klaunberg BA, Nestle FO, Castillo SS, Dennis PA and Hwang ST (2003) Immune evasion by murine melanoma mediated through CC chemokine receptor-10. J. Exp. Med. 198: 1337-1347

43. Stewart AL, Mhashilkar AM, Yang XH, Ekmekcioglu S, Saito Y, Sieger K, Schrock R, Onishi E, Swanson X, Mumm JB, Zumstein L, Watson GJ, Snary D, Roth JA, Grimm EA, Ramesh R and Chada S (2002) PI3 kinase blockade by Ad-PTEN inhibits invasion and induces apoptosis in RGP and metastatic melanoma cells. Mol. Med. 8: 451-461

44. Zhou XP, Gimm O, Hampel H, Niemann T, Walker MJ and Eng C (2000) Epigenetic PTEN silencing in malignant melanomas without PTEN mutation. Am. J. Pathol. 157: 1123-1128

45. Miyashita T, Kawakami A, Tamai M, Izumi Y, Mingguo H, Tanaka F, Abiru S, Nakashima K, Iwanaga N, Aratake K, Kamachi M, Arima K, Ida H, Migita K, Origuchi T, Tagashira S, Nishikaku F and Eguchi K (2003) Akt is an endogenous inhibitor toward tumor necrosis factor-related apoptosis inducing ligand-mediated apoptosis in rheumatoid synovial cells. Biochem. Biophys. Res. Commun. 312: 397-404

46. Schulze-Bergkamen H, Brenner D, Krueger A, Suess D, Fas SC, Frey CR, Dax A, Zink D, Buchler P, Muller M and Krammer PH (2004) Hepatocyte growth factor induces Mcl-1 in primary human hepatocytes and inhibits CD95mediated apoptosis via Akt. Hepatology 39: 645-654

47. Huang CL, Nordlund JJ and Boissy R (2002) Vitiligo: a manifestation of apoptosis? Am. J. Clin. Dermatol. 3: 301-308

48. Moretti S, Spallanzani A, Amato L, Hautmann G, Gallerani I, Fabiani M and Fabbri $P$ (2002) New insights into the pathogenesis of vitiligo: imbalance of epidermal cytokines at sites of lesions. Pigment Cell Res. 15: 87-92

49. Hachiya A, Kobayashi A, Ohuchi A, Takema Y and Imokawa G (2001 The paracrine role of stem cell factor/c-kit signaling in the activation of human melanocytes in ultraviolet-B-induced pigmentation. J. Invest. Dermatol. 116: 578-586

50. Autier P, Severi G, Pedeux R, Cattaruzza MS, Boniol M, Grivegnee A and Dore JF (2003) Number, size of nevi are influenced by different sun exposure components: implications for the etiology of cutaneous melanoma (Belgium, Germany, France, Italy). Cancer Causes Control 14: 453-459

51. Kunisada T, Yoshida H, Yamazaki H, Miyamoto A, Hemmi H, Nishimura E, Shultz LD, Nishikawa S and Hayashi S (1998b) Transgene expression of steel factor in the basal layer of epidermis promotes survival, proliferation, differentiation and migration of melanocyte precursors. Development 125: 2915-2923

52. Ashkenazi A, Pai RC, Fong S, Leung S, Lawrence DA, Marsters SA, Blackie C, Chang L, McMurtrey AE, Hebert A, DeForge L, Koumenis IL, Lewis D, Harris L, Bussiere J, Koeppen H, Shahrokh Z and Schwall RH (1999) Safety, antitumor activity of recombinant soluble Apo2 ligand. J. Cell. Invest. 104: 155-162

53. Chaussade $C$, Pirola L, Bonnafous S, Blondeau F, Brenz-Verca S, Tronchere H, Portis F, Rusconi S, Payrastre B, Laporte J and Van Obberghen E (2003) Expression of myotubularin by an adenoviral vector demonstrates its function as a Ptdlns(3)P phosphatase in muscle cell lines. Involvement of Ptdlns(3)P in insulin-stimulated glucose transport. Mol. Endocrinol. 17: 2448-2460

54. Gaggioli C, Busca R, Abbe P, Ortonne JP and Ballotti R (2003) Microphthalmiaassociated transcription factor (MITF) is required but is not sufficient to induce the expression of melanogenic genes. Pigment Cell Res. 16: 374-382 